\title{
Pelatihan E-commerce dan Pemulihan Ekonomi Nasional: Pengembangan Industri Kreatif Produk Unggulan Kota Tasikmalaya
}

\author{
Eko Nursanty*1, Djoko Darmawan², I Wayan Andhika Widiantara3
}

1,2,3Arsitektur, Fakultas Teknik, Universitas 17 Agustus 1945 (UNTAG) Semarang, Indonesia

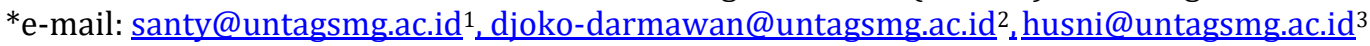

\begin{abstract}
Abstrak
Pandemik yang telah berlangsung lebih dari satu tahun memberikan dampak yang cukup signifikan berupa menurunnya pertumbuhan ekonomi masyarakat dunia, tidak terkecuali masyarakat Indonesia. Kota Tasikmalaya yang memiliki sejumlah pengrajin juga tidak terkecualikan. Kegiatan ini bertujuan untuk memberikan kemampuan lebih bagi para pengusaha dalam mengembangkan produk baik peingkatan mutu, pengemasan dan terakhir pemasaran secara elektronik. Produk yang telah dikenal luas secara lokal dan nasional, diupayakan mampu juga dikenal secara internasional. Metode yang dilakukan berupa daring dan luring. Sebagian narasumber membimbing secara langsung di lapangan pada workshop teknis yang dilaksanakan secara langsung dan narasumber lain memberikan materi pengetahuan melalui media daring. Hasil kegiatan ini diharapkan munculnya produk-produk lokal bertaraf internasional dan mampu berkembang menjadi Industri Kreatif unggulan Kota Tasikmalaya. Selain mampu memberikan nilai tambah dan ketangguhan ekonomi, produk-produk unggulan ini dianggap mampu memberikan nilai otentik yang tinggi pada identitas kota Tasikmalaya guna memenangkan persaingan antar kota.
\end{abstract}

Kata kunci: E-commerce, Industri Kreatif, Tasikmalaya

\begin{abstract}
Pandemics that have lasted more than one year have a significant impact in the form of declining economic growth of the world community, not least the people of Indonesia. The city of Tasikmalaya which has a number of craftsmen is also no exception. This activity aims to provide more ability for entrepreneurs in developing products both quality improvement, packaging and finally electronic marketing. Products that have been widely known locally and nationally, are also known internationally. The method is done online and offline. Some sources guide directly in the field in technical workshops that are carried out directly and other sources provide knowledge materials through online media. The results of the activities are expected to appear in international standard local products after this activity and develop into the flagship Creative Industries of Tasikmalaya City. In addition to being able to provide added value and economic toughness, these superior products are considered able to provide high authentic value to the identity of tasikmalaya city to win competition between cities.
\end{abstract}

Keywords: Creative Industry, E-commerce, Tasikmalaya

\section{PENDAHULUAN}

Pertumbuhan dalam perekonomian yang dilakukan oleh penduduk lokal merupakan sebuah proses bersama antara pemerintah daerah dan komunitas masyarakat terlibat didalam upaya-upaya untuk mendorong, serta menumbuhkan dan memelihara segala aktivitas usaha agar dapat menciptakan lapangan pekerjaan. Kegiatan ini bertujuan memberi gambaran berupa upaya yang telah dilakukan pihak pemerintah daerah dalam mengembangkan bidang ekonomi lokal masyarakatnya.

Penelitian yang pernah dilakukan pernah memberi gambaran mengenai 8 (delapan) elemen yang termasuk dalam jenis ekonomi local, yaitu: produk makanan, pelayanan social, produk-produk lokal, para pengrajin, seniman, pengusaha-pengusaha mandiri, system distribusi dan pelayanan makanan (Kurniawan, 2010) dan tergambar pada Gambar 1.

Pemerintah Indonesia juga telah melakukan berbagai upaya dalam meningkatkan pembangunan dan pelayanan masyarakat di daerah dalam rangka menumbuhkan ekonomi lokal masyarakat. Undang-Undang Nomor 24 tahun 2019 yang telah mengatur perihal ekonomi lokal yang kreatif diciptakan dengan tujuan untuk melakukan optimalisasi kreativitas yang menjadi 
sumber daya manusia yang yang menggunakan warisan budaya, ilmu pengetahuan, serta teknologi sebagai landasan utamnya.

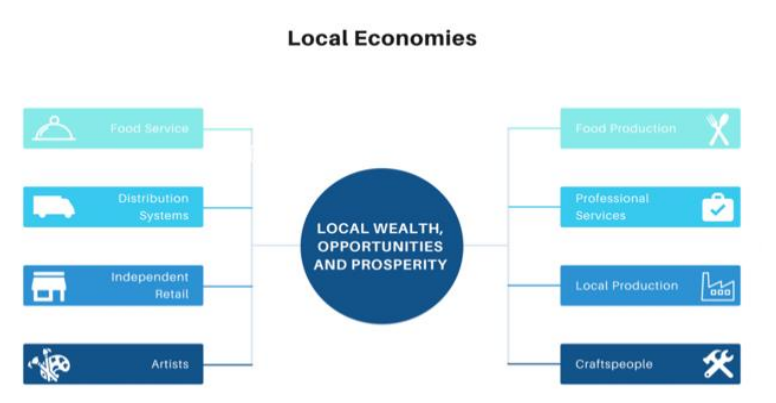

Gambar 1. Diagram peran ekonomi lokal bagi kemakmuran dan peluang sebuah kota

Pengelolaan ekonomi lokal yang kreatif beserta potensi yang dimilikinya perlu diupayakan agar senantiasa berkesinambungan dan sistematis, terstruktur. Pengembangan ruang lingkup ekonomi kreatif mampu memberikan nilai tambah pada produk Ekonomi Kreatif agar memiliki kemampuan bersaing, mudah dan cepat diakses, serta memiliki perlindungan hukum. Dalam Pasal 33 ayat (4) Undang-Undang Dasar Negara Republik Indonesia Tahun 1945 mengamanatkan bahwasanya kondisi perkembangan perekonomian nasional di Indonesia senantiasa diselenggarakan berdasarkan atas demokrasi berupa demokrasi ekonomi dengan prinsip-prinsip utamanya berupa kebersamaan yang berkeadilan, juga berkelanjutan serta berwawasan lingkungan.

Ekonomi kreatif bertujuan agar: (i) mampu memberikan dorongan pada beragam aspek ekonomi kreatif yang sesuai dengan perkembangan kebudayaan dan masyarakat, teknologi yang dimiliki, kreativitas, serta inovasi masyarakat Indonesia; (ii) mampu memberikan kesejahteraan bagi rakyat Indonesia dengan munculnya peningkatan devisa negara; (iii) menciptakan iklim ekonomi yang kreatif serta berdaya saing; (iv) mampu menciptakan peluang kerja baru pada nilai bidang seni dan budaya bangsa Indonesia sebagai bagian sumber daya ekonomi lokal; (v) melakukan optimalisasi pada potensi pelaku ekonomi kerakyatan; (vi) mampu memberikan erlindungan pada hasil kreativitas pelaku ekonomi kreatif; dan (Malizia et al., 2020).

Agar dapat tercapai bentuk optimalisasi sumber daya manusia yang diharapkan, perluadanya upaya pengelolaan potensi sumber daya ekonomi kreatif yang sistematis, Dengan demikian diperlukan sistim yang memadai pada ekonomi kreatif yang termaktup dalam perencanaan pembangunan nasional yang telah dilakukan melalui pengembangan ekosistem Ekonomi Kreatif yang mampu memberikan sebuah keunggulan dan nilai unggulan tambah pada produk Ekonomi Kreatif yang berdaya saing tinggi membanggakan, juga mudah diakses, dan tentunya terlindungi secara hukum (Satria, 2011).

Proses pelaksanaannya, pengembangan ekonomi kreatif yang telah berlangsung selama ini mengalami beberapa kendala, serta keterbatasan pada kemampuan melakukan akses perbankan, bidang promosi, infrastruktur yang ada, serta pengembangan kapasitas para pelaku ekonomi kreatif (Blakely \& Leigh, 2013). Dalam ekonomi lokal, warung dan toko sering dimiliki secara independen oleh individu, keluarga, atau sekelompok kecil orang. Karakteristik yang unik adalah bahwa orang-orang ini juga merupakan bagian dari komunitas. Mereka adalah orangorang di lingkungan Anda. Ekonomi lokal lebih bersifat pribadi. Interaksi antara pemilik dan penduduk dapat menciptakan hubungan yang tahan lama dan dihargai (Hermawan, 2016).

Hubungan yang lebih kuat ini mampu menyebabkan peningkatan modal sosial. Mereka juga dapat mengarah pada layanan pelanggan yang lebih baik. Pemilik bisnis lokal dapat menyesuaikan produk dan layanan mereka kepada penduduk, daripada ditekan untuk mematuhi strategi pemasaran nasional yang diterapkan oleh rantai distribusi.

Selain itu, penelitian yang telah dilakukan sebelumnya, menunjukkan bahwa bisnis lokal lebih mungkin untuk menyumbang ke badan amal lokal yang mendukung masyarakat. Pemilik bisnis lokal lebih banyak berinvestasi di masyarakat. Oleh karena itu, mereka lebih bersedia 
menyumbangkan waktu dan uang mereka. Jenis dukungan akar rumput ini memajukan ekonomi lokal dan menciptakan peluang tambahan bagi penduduknya (Perry, 2010). Di sisi lain, ekonomi lokal membantu melestarikan kualitas unik masyarakat dan memberikannya karakter khas. Sebuah toko dan pengecernya dikaitkan dengan keseragaman dan kurangnya orisinalitas. Sebaliknya, bisnis lokal mampu berkontribusi pada citra diri positif masyarakat. Atribut unik menciptakan rasa bangga yang menyebabkan peningkatan pariwisata dan kegiatan ekonomi. Ekonomi lokal memiliki dampak positif pada pekerjaan. Menurut Small Business Administration, usaha kecil mempekerjakan 49,2\% dari tenaga kerja sektor swasta (Syadzali, 2020).

Pemilik bisnis lokal lebih banyak berinvestasi di lingkungan komunitas mereka dan cenderung tinggal di sana lebih lama, yang mengarah ke peningkatan lapangan kerja. Peningkatan lapangan kerja dan stabilitas berarti lebih banyak peluang bagi penduduk, yang dapat meningkatkan kekayaan lokal. Selain itu, ekonomi lokal seringkali lebih efisien. Misalnya, toko kelontong lokal lebih cenderung membeli produk mereka dari pertanian terdekat daripada supermarket multinasional besar. Biaya transportasi yang lebih rendah mengurangi biaya bagi konsumen (Martati \& Syarifuddin, 2013). Peningkatan efisiensi tidak hanya menguntungkan pelanggan tetapi juga lingkungan. Lebih sedikit transportasi berarti lebih sedikit konsumsi bahan bakar, polusi dan kemacetan menciptakan komunitas yang lebih berkelanjutan dan sehat. Jika kita ingin mencapai komunitas yang benar-benar berkelanjutan, kita harus menyeimbangkan pengaruh globalisasi melalui investasi di ekonomi lokal yang mendorong pengembangan masyarakat dan modal sosial (Hasan \& Azis, 2018).

Proporsi uang yang lebih tinggi yang dihabiskan kembali dalam ekonomi lokal berarti memilik efek pengganda yang lebih tinggi karena lebih banyak pendapatan dihasilkan bagi masyarakat setempat. Semakin banyak pendapatan yang Anda pertahankan secara lokal, atau nasional, berarti lebih banyak pekerjaan, gaji yang lebih tinggi dan lebih banyak pendapatan pajak bagi pemerintah, yang semuanya mengarah pada standar hidup yang lebih baik (Budiharsono, 2015).

Tujuan dari kegiatan pengabdian masyarakat ini adalah membantu memperkuat kemampuan para pengusaha lokal dalam memenangkan persaingan global dalam bentuk berbagai upaya mulai dari pengolahan produksi, kemasan produk sampai dengan pemasaran baik secara luring maupun daring. Khususnya di kota Tasikmalaya.

\section{METODE}

Tabel 1. Jadwal kegiatan pengabdian masyarakat

\begin{tabular}{|c|c|c|c|c|}
\hline $\mathbf{J P}$ & Pukul & Materi & Pemateri & Room \\
\hline \multicolumn{5}{|c|}{ 09-12 November 2020} \\
\hline 1 & $08.00-08.45$ & Pengembangan Sumber Daya Manusia & Ir.Djoko Darmawan,MT & \multirow{7}{*}{ Room 1} \\
\hline 2 & $\begin{array}{l}08.45-09.30 \\
09.30-10.00\end{array}$ & Pengembangan Sumber Daya Manusia & Ir.Djoko Darmawan,MT & \\
\hline 3 & $10.00-10.45$ & Pengenalan Heritage/Warisan Budaya dalam & Dr (Ars).Eko & \\
\hline \multirow[t]{2}{*}{4} & $10.45-11.30$ & $\begin{array}{c}\text { Pengembangan Produk } \\
\text { Pengenalan Heritage/Warisan Budaya dalam } \\
\text { Pengembangan Produk }\end{array}$ & $\begin{array}{l}\text { Nursanty,S.T.,M.T } \\
\text { Dr (Ars).Eko } \\
\text { Nursanty,S.T.,M.T }\end{array}$ & \\
\hline & $11.30-13.00$ & & & \\
\hline 5 & $13.00-13.45$ & Pengenalan Potensi Ekspor & I Wayan Andhika,ST.,M.Ars & \\
\hline 6 & $13.45-14.30$ & Pengenalan Potensi Ekspor & I Wayan Andhika,ST.,M.Ars & \\
\hline 1 & $08.00-08.45$ & Pengenalan Potensi Ekspor & $\begin{array}{l}\text { Dipl,-Ing(FH) Rajiv } \\
\text { Maulana }\end{array}$ & \multirow{5}{*}{ Room 2} \\
\hline 2 & $08.45-08.30$ & Pengenalan Potensi Ekspor & $\begin{array}{l}\text { Dipl,-Ing(FH) Rajiv } \\
\text { Maulana }\end{array}$ & \\
\hline 3 & $\begin{array}{l}09.30-10.00 \\
10.00-10.45\end{array}$ & Pengembangan Sumber Daya Manusia & Ir.Djoko Darmawan,MT & \\
\hline 4 & $\begin{array}{l}10.45-11.30 \\
11.30-13.00\end{array}$ & Pengembangan Sumber Daya Manusia & Ir.Djoko Darmawan,MT & \\
\hline 5 & $13.00-13.45$ & $\begin{array}{l}\text { Pengenalan Heritage/Warisan Budaya dalam } \\
\text { Pengembangan Produk }\end{array}$ & $\begin{array}{c}\text { Dr (Ars).Eko } \\
\text { Nursanty,S.T.,M.T }\end{array}$ & \\
\hline
\end{tabular}


Kegiatan ini menggunakan dua metode penyuluhan baik secara luring berupa workshop langsung di kota Tasikmalaya dan daring yang dilakukan menggunakan media zoom meeting. Workshop secara luring dilakukan oleh pemateri yang memberikan materinya berupa kegiatan teknis seperti: pemotretan produk dan pembuatan took online pada aplikasi Tokopedia dan Bukalapak. Materi yang diberikan antara lain: Fitur dan Fasilitas bagi Seller untuk Meningkatkan Penjualan di Tokopedia; Fitur dan Fasilitas bagi Seller untuk Meningkatkan Penjualan di Bukalapak.

Sedangkan workshop secara daring dilakukan oleh pemateri yang memberikan materinya berupa teori-teori, antara lain: Pengembagan Sumber Daya Manusia; Pengenalan Heritage/Warisan Budaya dalam Pengembangan Produk; Pengenalan Potensi Ekspor; Penggunaan Teknologi Pangan Tepat Guna (Khusus Peserta Produsen Olahan Pangan) dan Pengembangan Handcraft dan Kerajinan (Khusus Peserta Produsen Non-Olahan Pangan).

\section{HASIL DAN PEMBAHASAN}

Kegiatan ini diikuti oleh 1000 (seribu) pengusaha lokal kota Tasikmalaya uang terdiri atas produsen dari 9 (sembilan) produk unggulan, yaitu: (1) Produsen Makanan Olahan; (2) Konveksi; (3) Pengrajin Batik; (4) Pengrajin Bordir; (5) Pengrajin Payung Geulis; (6) Pengrajin Sendal/Kelom Geulis; (7) Pengrajin Anyaman Mendong; (8) Pengrajin Anyaman Bambu Pengrajin Ukiran Kayu. Sedangkan materi kegiatan terbagi atas dua kelompok utama, yaitu kelompok materi offline dan online.

Untuk kegiatan Basis secara offline atau luring dapat dilihat pada gambar 2 dibawah. Materi terdiri atas teori-teori mengenai: Over View Materi produk; Strategi Perhitungan Bisnis Dasar; Pengoptimalan Sosial Media \& Copywriting; Teknik Fotografi Aplikatif \& Tepat Guna; Teknik Pengelolaan dan Optimasi Marketplace.

Setelah tahap pelatihan offline atau luring, para peserta dilanjutkan dengan pelatihan tahap online atau luring, dengan materi sebagai berikut: (a) Materi Umum, berupa materi teoriteori: Pengembangan sumber daya manusia dan karyawan dan Pengenalan Heritage/Warisan Budaya dalam Pengembangan Produk. (b) Materi khusus, terdiri atas: Pengenalan teknologi pangan tepat guna (Khusus peserta produsen olahan pangan); Pengembangan handcraft dan kerajinan (Khusus peserta produsen non olahan pangan); Pelatihan pemasaran online oleh Tokopedia: Fitur dan fasilitas bagi seller untuk meningkatkan penjualan di Tokopedia; Pelatihan pemasaran online oleh Bukalapak: Fitur dan fasilitas bagi seller untuk meningkatkan penjualan di Bukalapak.

\subsection{Pelatihan Pengembangan Sumber Daya Manusia}

Dalam Pelatihan Pengembangan Sumber daya Manusia, IKM secara interaktif diajarkan bagaimana cara memilih, mengelola, dan mengembangkan sumber daya manusia secara tepat sehingga pengelolaan usaha lebih efektif dan efisien terutama di masa pandemi ini. Pengenalan Heritage/Warisan Budaya dalam Pengembangan Produk, menghasilkan dimana IKM secara interaktf diajarkan bagaimana mengenali warisan budaya di sekitar dan mengaplikasikan nilainilai warisan budaya tersebut baik sejarah, bangunan, tokoh, tempat, perilaku, dll, ke dalam branding sebuah produk. Pada materi Pengenalan Potensi Ekspor, IKM secara interaktf diajarkan mengenali bagaimana kriteria produk-produk potensial dan terstandar untuk ekspor. IKM juga digambarkan secara umum bagaimana kondisi dan persyaratan dasar baik dari sisi produk maupun unit perusahaan dalam melakukan ekspor.

\subsection{Penggunaan Teknologi Pangan Tepat Guna}

Penggunaan Teknologi Pangan Tepat Guna, menghasilkan manfaat dimana IKM pangan secara interaktf diajarkan bagaimana mengolah produk olahan pangan yang baik serta apa saja alterntif-alternatif teknologi maupun bahan tepat guna yang bisa diaplikasikan untuk menjawab permasalahan-permasalahan berkaitan dengan olahan pangan tersebut yang selama ini dihadapi oleh IKM. 


\subsection{Gambar Survey}

Gambar 2 dibawah adalah suasana pelatihan secara luring yang dilakukan secara offline di kantor Dinas Perdagangan Kota Tasikmalaya.
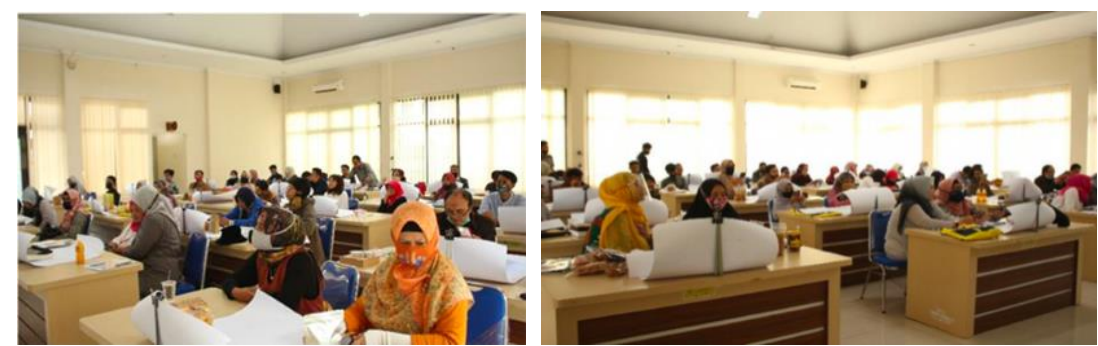

Gambar 3. Tim Tokopedia dan Bukalapak membimbing optimalisasi penjualan $e$-commerce
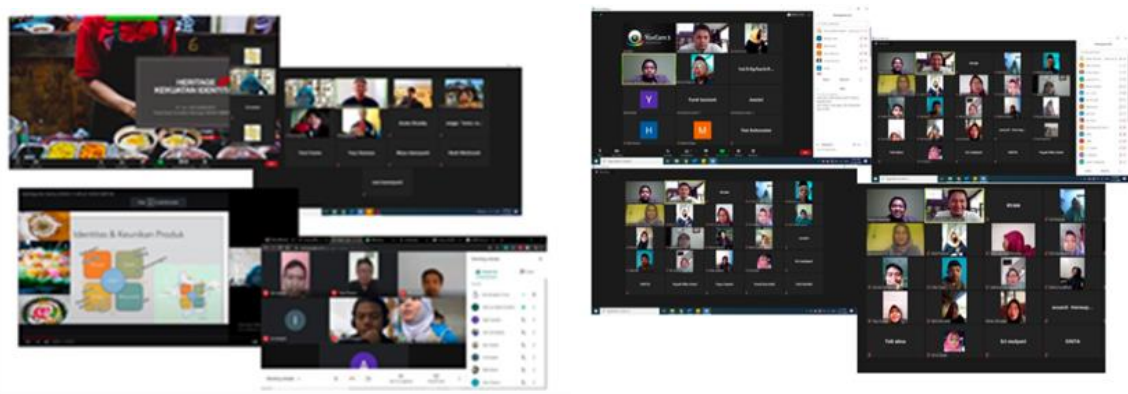

Gambar 4. Narasumber melakukan pembimbingan

Gambar 3 diatas menggambarkan suasana pelatihan yang dilakukan daring dengan berbagai materri teori yang ada.

Berdasarkan hasil masukan para peserta setelah kegiatan, ditemukan berbagai pendapat yang telah dikelompokkan menjadi beberapa kelompok masukan sebagai gambaran hasil kegiatan, sebagai berikut: Materi luring yang diberikan oleh aplikasi online Tokopedia dan Buka Lapak dianggap sangat menarik oleh para peserta namun demikian sentuhan-sentuhan khusus untuk memenangkan persaingan menjadi hal yang sangat penting dan baru mereka pelajari sekarang, misalnya Teknik pemotretan produk, kemasan personal dan penjualan dengan model desain-desain khusus yang siap menjadi hadiah unik, meskipun barang yg dijual cukup sederhana.

Tokopedia adalah salah satu startup karya kebanggaan putra bangsa yang berdiri sejak 2014. Meskipun diawali dengan berbagai masalah saat awal didirikan. Salah satu hal yang dikeluhkan mengenai Tokopedia adalah sering dikeluhkan oleh pelanggan berupa terlalu sering proses maintenance yang mengakibatkan terganggunya kegiatan belanja atau berjualan sehingga menimbulkan hambatan serta ketidak nyamanan. Para seller sering melakukan persaingan harga pada marketplace ini sehingga produk yang dijual sedikit lebih tinggi yang mana menimplkan dampak dimana lebih kecil untuk diminati. Terakhir, pada bagian pengelolaan bagian stok belum dioptimalkan sehingga stok produk belum secara otomatis diperbarui setelah terjadi pembelian.

Selain Tokopedia, Bukalapak juga merupakan startup karya anak bangsa yang juga sangat diminati dengan waktu relatif singkat. Marketplace ini hadir dengan beragam kelebihan inovasi terbaru berbasis teknologi canggih. Yang cukup menonjol adalah tampilannya yang menarik serta kemampuan untuk menambahkan gambar hingga 5 gambar sekaligus dengan system drop dan drag. Sedangkan kelemahan Bukalapak menurut para peserta, Saat dicari dengan search engine Bukalapak cukup sulit ditemukan karena kurangnya optimasi SEO. Sistem pencairan dana dari Bukadompetnya Bukalapak tergolong cukup lama, bahkan terkadang membutuhkan waktu yang lebih dari satu hari. Yang terakhir, Dimensi ruang yang disediakan pada fitur deskripsi barang yang diperdagangkan dianggap sempit dan tidak terlalu mencukupi. Akibatnya tag html kerap terbawa pada tulisan dan juga sering error. 


\section{KESIMPULAN}

Penguatan ekonomi lokal adalah kunci ketahanan ekonomi suatu bangsa. Pembangunan ekonomi lokal yang efektif dapat mengurangi kesenjangan antara tempat-tempat miskin dan kaya, menambah lowongan pekerjaan dan perusahaan yang dihasilkan secara lokal, meningkatkan investasi sektor swasta secara keseluruhan, meningkatkan arus informasi dengan investor dan pengembang, serta meningkatkan koherensi dan kepercayaan yang dengannya strategi ekonomi lokal mampu diraih. Pengembangan ekonomi masyarakat atau pembangunan ekonomi lokal adalah proses masyarakat di mana masyarakat mengidentifikasi dan menemukan pemecaham masalah mereka sendiri pada masalah ekonomi, sosial dan lingkungan guna membangun tujuan Bersama berupa masyarakat yang sehat dan layak secara ekonomi. Prinsip dan tujuannya berdasarkan pendekatan akar rumput untuk pembangunan di mana masyarakat memilih tindakan yang disengaja untuk mempengaruhi ekonomi lokal dan meningkatkan kualitas hidup untuk tujuannya.

Setiap bisnis, pekerjaan, dan institusi dalam komunitas bergantung pada orang lain. Pekerja dan pekerjaan menciptakan efek riak karena orang menghabiskan uang untuk barang dan jasa lokal. Bisnis juga menghabiskan uang secara lokal dan dapat membantu bisnis baru muncul untuk hidup. Dimasa depan diharapkan masyarakat UMKM kota Tasikmalaya mampu mengembangkan potensi bisnis yang dimilikinya menggunakan materi-materi pelatihan yang telah diberikan agar mampu menumbuhkan kemampuan bersaing produk yang dimilikinya.

\section{UCAPAN TERIMA KASIH}

Penulis menyampaikan ucapan terima kasih kepada Pemerintah Kota Tasikmalaya dan Dinas Perdagangan dan Perindustrian Kota Tasikmalaya atas terselengggaranya kegiatan ini. Terima kasih juga disampaikan kepada GIZ German yang telah memilih penulis menjadi salah satu dari tim pelaksana dan membantu secara finansial atas kelancaran seluruh kegiatan.

\section{DAFTAR PUSTAKA}

Blakely, E. J., \& Leigh, N. G. (2013). Planning local economic development. Sage.

Budiharsono, S. (2015). Pengembangan Ekonomi Lokal dan Daerah untuk Meningkatkan Daya Saing Daerah. Bogor.

Hasan, M., \& Azis, M. (2018). Pembangunan Ekonomi \& Pemberdayaan Masyarakat: Strategi Pembangunan Manusia dalam Perspektif Ekonomi Lokal. CV. Nur Lina Bekerjasama dengan Pustaka Taman Ilmu.

Hermawan, H. (2016). Dampak pengembangan Desa Wisata Nglanggeran terhadap ekonomi masyarakat lokal. Jurnal Pariwisata, 3(2), 105-117.

Kurniawan, D. (2010). ALTERNATIF PENGEMBANGAN EKONOMI LOKAL DI KOTA. Name: Jurnal Perencanaan Wilayah Dan Kota, 21(1), 19-36.

Malizia, E., Feser, E., Renski, H., \& Drucker, J. (2020). Understanding local economic development. Routledge.

Martati, I., \& Syarifuddin, A. (2013). Model Penciptaan Lapangan Kerja Melalui Pengembangan Ekonomi Lokal Pada Kecamatan Samarinda Ilir. Jurnal Manajemen Dan Kewirausahaan (Journal of Management and Entrepreneurship), 15(2), 123-130.

Perry, M. (2010). Controversies in local economic development: Stories, strategies, solutions. Routledge.

Satria, D. (2011). Strategi Pengembangan Industri Kreatif untuk Meningkatkan Daya Saing Pelaku Ekonomi Lokal. Jurnal Aplikasi Manajemen, 9(1), 301-308.

Syadzali, M. M. (2020). Model Pemberdayaan Masyarakat Melalui Pengembangan Ekonomi Lokal (Studi pada UKM Pembuat Kopi Muria). Syntax, 2(5). 